gp38 $8^{+}$cells: mRNA and protein levels of the profibrotic genes $\alpha$ SMA and collagen I were significantly downregulated $(n=5 ; p=0.007)$. Moreover, Fra2 downregulation impaired the secretion of collagens $(n=4 ; p<0.05)$ and the formation of $\alpha$ SMA fibers $(n=3)$ in addition to a significant downregulation of $m R N A$ and protein expression of LC3B, Beclin and Atg5 ( $n=3)$

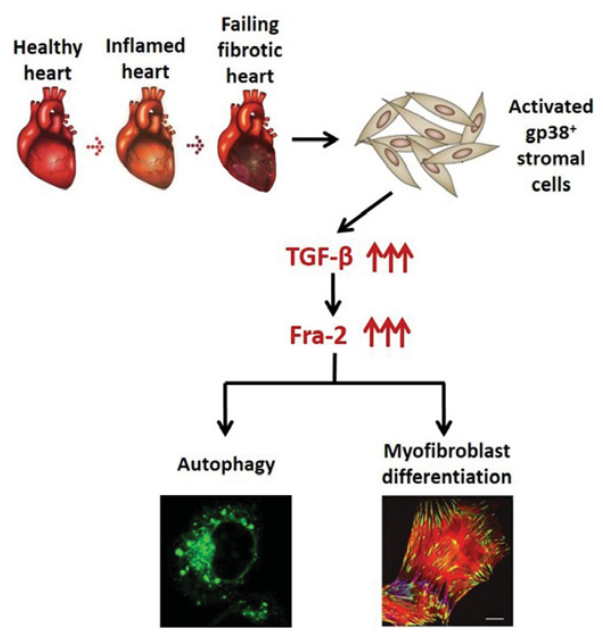

Conclusions: The TGF- $\beta /$ Fra2 axis fosters an enhanced autophagy flow, leading in turn to the stromal-to-myofibroblast transition. Therefore, targeting this process might be a therapeutic strategy to abrogate fatal cardiac remodeling in SSc Disclosure of Interest: M. Stellato: None declared, M. Rudnik: None declared, F. Renoux: None declared, E. Pachera: None declared, D. Kayalar: None declared, K. Sotlar: None declared, K. Klingel: None declared, J. Henes: None declared, P. Blyszczuk: None declared, O. Distler Grant/research support from: Actelion, Bayer, Boehringer Ingelheim, Pfizer, Sanofi, Consultant for: 4 D Science, Actelion, Active Biotec, Bayer, Biogenldec, BMS, Boehringer Ingelheim, ChemomAb, EpiPharm, espeRare foundation, Genentech/Roche, GSK, Inventiva, Lilly, medac, Mepha, Medlmmune, Mitsubishi Tanabe Pharma, Pharmacyclics, Pfizer, Sanofi, Serodapharm, Sinoxa, Speakers bureau: AbbVie, iQone Healthcare, Mepha, G. Kania Grant/research support from: Bayer AG

DOI: 10.1136/annrheumdis-2017-eular.3760

\section{OP0085 LONGITUDINAL ANALYSIS OF THE GASTROINTESTINAL MICROBIOTA IN SYSTEMIC SCLEROSIS}

E.R. Volkmann ${ }^{1}$, A.-M. Hoffmann-Vold ${ }^{2}$, Y.-L. Chang ${ }^{1}$, J. Jacobs ${ }^{1}$, K. Tillisch ${ }^{1}$, E. Mayer ${ }^{1}$, P.J. Clements ${ }^{1}$, J. Hov $^{2}$, M. Kummen ${ }^{2}$, Ø. Midtvedt ${ }^{2}$, V. Lagishetty ${ }^{1}$, $\varnothing$. Molberg ${ }^{2}$, J. Braun ${ }^{1}$. ${ }^{1}$ University of California, Los Angeles, Los Angeles, United States; ${ }^{2}$ Oslo University Hospital, Oslo, Norway

Background: Gastrointestinal tract (GIT) dysfunction affects the majority of patients with systemic sclerosis (SSc). While the etiology of SSc-related lower GIT dysfunction remains elusive, we have recently demonstrated that the SSc disease state is associated with a distinct colonic microbial consortium and that specific genera are associated with SSc-GIT symptoms in a cross-sectional analysis using colonic lavage specimens. ${ }^{1}$

Objectives: To evaluate changes in GIT microbial composition over time in relation to GIT symptoms in SSc patients.

Methods: Adults SSc patients not on chronic antibiotic therapy were eligible to participate. Stool specimens were collected at $0,3,6,9$, and 12 months. Healthy controls were matched to SSc patients in a $1: 1$ ratio at baseline. SSc patients completed the GIT 2.0 questionnaire to assess GIT symptom severity at each collection time. The microbiota from these samples were determined by Illumina HiSeq 250016 S sequencing. Linear Discriminant Analysis Effect Size was used to identify the genera that showed differential expression in SSc versus controls. Mixed models evaluated changes in GIT symptoms and microbial composition over time.

Results: Among 17 patients with SSc (88\% Female; Median age 52.1 years), the mean (SD) baseline total GIT 2.0 score was $0.7(0.6)$. The majority of participants $(71 \%)$ provided at least 4 stool samples over the course of the 12-month study. Principal coordinate analysis illustrated significant microbial community differences in SSc versus healthy controls $(p=0.001)$. Consistent with the results of our prior study using colonic lavage specimens, ${ }^{1}$ SSc patients had decreased commensal genera, such as Faecalibacterium and Bacteroides and increased pathobiont genera, such as Fusobacterium and Erwinia compared with healthy controls (Figure 1). GIT 2.0 scores did not change significantly over the course of the 12-month study for each subject. However, patients with longer disease durations had increased GIT symptoms over time for the total score $(P=0.0038)$, and the following domains: fecal soilage $(P=0.0217)$, social functioning $(\mathrm{P}=0.0116)$, emotional well-being $(\mathrm{P}=0.0474)$, and constipation $(P=0.0039)$. There was no difference in the course of GIT symptoms over time between patients with limited versus diffuse cutaneous disease. Both the absolute and relative abundances of specific genera did not change over time within individual subjects. After controlling for age, gender, ethnicity, disease duration and SSc subtype (i.e. limited vs. diffuse), low abundance of Bacteroides was associated with increased GIT symptoms over time.

Figure 1. Genus level taxa associated with UCLA-SSc patients versus healthy subjects. Negative and positive effect sizes denote genera decreased (blue) or increased (red) in SSc patients, respectively.

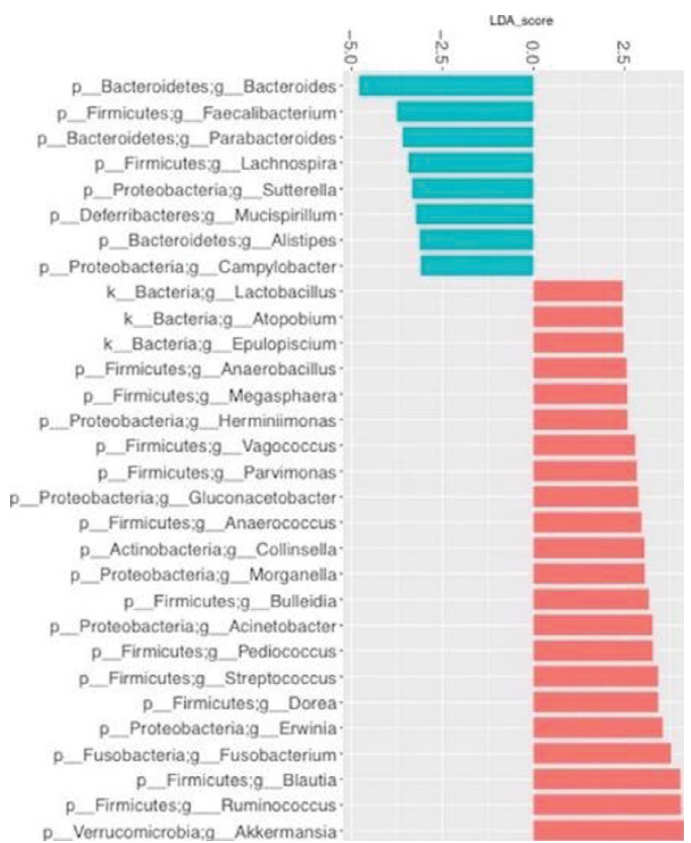

Conclusions: This study is the first to characterize lower GIT microbiota in SSc patients at multiple time points. The findings provide further evidence that lower GIT dysbiosis is a feature of the SSc disease state and that specific genera may contribute to GIT symptoms and serve as potential targets for therapeutic intervention.

References:

[1] Volkmann et al. Arthritis Rheumatol 2016;68:1483

Disclosure of Interest: None declared

DOI: 10.1136/annrheumdis-2017-eular.2077

\section{OP0086 LONG NONCODING RNA H19X AS A NEW THERAPEUTIC TARGET FOR FIBROSIS}

E. Pachera ${ }^{1}$, A. Wunderlin ${ }^{1}$, S. Assassi ${ }^{2}$, G. Salazar ${ }^{2}$, M. Frank-Bertoncelj ${ }^{1}$, R. Dobrota ${ }^{1}$, M. Brock ${ }^{3}$, C. Feghali-Bostwick ${ }^{4}$, G. Gerhard Rogler ${ }^{5}$,

G. Dijkstra ${ }^{6}$, T. van Haaften ${ }^{5}$, J. Distler ${ }^{7}$, G. Kania ${ }^{1}, O$. Distler ${ }^{1} .{ }^{1}$ Center of Experimental Rheumatology, University Hospital Zurich, Zurich, Switzerland; ${ }^{2}$ Department of Internal Medicine, University of Texas, Houston, United States, ${ }^{3}$ Department of Pulmonology, University Hospital Zurich, Zurich, Switzerland;

${ }^{4}$ Division of Rheumatology, Medical University of South Carolina, Charleston, United States; ${ }^{5}$ Department of Gastroenterology and Hepatology, University Hospital Zurich, Zurich, Switzerland; ${ }^{6}$ Department of Gastroenterology and Hepatology, University Medical Center Groningen, Groningen, Netherlands; ${ }^{7}$ Department of Internal Medicine 3, University of Erlangen, Erlangen, Germany

Background: Long noncoding RNAs (IncRNAs) are an emerging class of transcripts involved in the regulation of gene expression. We have recently identified a novel IncRNA, H19X, to be upregulated in systemic sclerosis (SSc). We also demonstrated that $\mathrm{H} 19 \mathrm{X}$ is a key mediator of TGF $\beta$-driven myofibroblast development and extracellular matrix synthesis.

Objectives: To assess whether (1) H19X upregulation in SSc fibroblast is antiapoptotic and pro-proliferative thereby favoring fibrosis (2) $\mathrm{H} 19 \mathrm{X}$ is a regulator of fibrotic diseases in general.

Methods: To study the function of H19X in apoptosis and proliferation of of dermal fibroblasts we silenced $\mathrm{H} 19 \mathrm{X}$ using locked nucleic acid oligonucleotides (LNA GapmeRs followed by microarray analysis, GPCR, BrdU cell proliferation assay, Caspase 3/7 apoptosis assay and scratch assay. Cells were treated with $10 \mathrm{ng} / \mathrm{ml} \mathrm{TGF} \beta$. Lung tissues were obtained from patients with SSc and idiopathic pulmonary fibrosis (IPF) undergoing transplantation, and from healthy controls $(\mathrm{HC})$. Resected gut tissue from fibrotic and non-fibrotic areas was obtained from Crohn's disease patients. Non-cancer-affected gut tissue from resections because of adenocarcinoma was used as control. Expression of H19X was analyzed by quantitative (q)PCR.

Results: H19X knockdown followed by microarray analysis $(n=5)$ showed that FAS signaling pathway, cyclins and cell cycle regulation, regulation of cell cycle progression by PIk3, and free radical induced apoptosis were among the 
pathways with the highest number of significantly enriched genes $(n=5 ; p<0.005)$. Apoptosis markers like BCL2, IGFBP3 and FAF1 $(n=5, p<0.05)$ were upregulated in H19X-silenced fibroblasts. This indicated that targeting H19X might have a pro-apoptotic effect on fibroblasts thereby protecting from fibrosis. Functional studies showed enhanced fibroblast apoptosis after H19X silencing and TGF $\beta$ stimulation $(n=5, p<0.05)$. In addition to decreased apoptosis, increased fibroblast proliferation might also favor fibrosis. Indeed, H19X downregulation led to reduced cell proliferation as measured by BrdU assay $(n=5, p<0.05)$. Scratch assay $(n=5)$ showed that H19X knockdown decreases TGF $\beta$ reduced wound healing. H19X expression was significantly increased in SSc interstitial lung disease and IPF patients versus $\mathrm{HC}(n=11$ each, $p<0.05)$. A significant $\mathrm{H} 19 X$ overexpression was also detected in fibrotic tissue from Crohn's disease patients $(n=4-10, p<0.05)$.

Conclusions: $\mathrm{H} 19 \mathrm{X}$ supports TGF $\beta$ driven fibrosis not only by favoring myofibroblast development and extracellular matrix synthesis, but also by inducing proliferation and reducing apoptosis of dermal fibroblasts. These effects are not limited to SSc, but appear operative in a wider range of fibrotic diseases. Our results highlight the IncRNA H19X as a potent new therapeutic target in fibrotic diseases opening thereby new possibilities for the treatment of TGF $\beta$ driven fibrosis.

Disclosure of Interest: E. Pachera: None declared, A. Wunderlin: None declared, S. Assassi Consultant for: Boehringer Ingelheim, Genentech and Biogen IDEC Inc., Bayer HealthCare, G. Salazar: None declared, M. Frank-Bertoncelj: None declared, R. Dobrota: None declared, M. Brock: None declared, C. FeghaliBostwick: None declared, G. Gerhard Rogler: None declared, G. Dijkstra: None declared, T. van Haaften: None declared, J. Distler Shareholder of: 4D Science, Grant/research support from: from Anamar, Active Biotech, Array Biopharma, BMS, Bayer Pharma, Boehringer Ingelheim, Celgene, GSK, Novartis, SanofiAventis, UCB, Consultant for: Actelion, Active Biotech, Anamar, Bayer Pharma, Boehringer Ingelheim, Celgene, Galapagos, GSK, Inventiva, JB Therapeutics, Medac, Pfizer, RuiYi and UCB., G. Kania Grant/research support from: Bayer, O. Distler Grant/research support from: Actelion, Bayer, Boehringer Ingelheim, Pfizer, Sanofi, Consultant for: 4 D Science, Actelion, Active Biotec, Bayer, Biogenldec, BMS, Boehringer Ingelheim, ChemomAb, EpiPharm, espeRare foundation, Genentech/Roche, GSK, Inventiva, Lilly, medac, Mepha, Medlmmune, Mitsubishi Tanabe Pharma, Pharmacyclics, Pfizer, Sanofi, Serodapharm, Sinoxa, Speakers bureau: AbbVie, iQone Healthcare, Mepha DOI: 10.1136/annrheumdis-2017-eular.4877

\section{OP0087 PLATELET-SPECIFIC FLI1-KNOCKOUT MICE SHOW ACCELERATED WOUND CLOSURE ASSOCIATED WITH INCREASED MYOFIBROBLAST FORMATION IN THE INFLAMMATORY PHASE}

M. Hirabayashi, Y. Asano, T. Yamashita, R. Saigusa, S. Miura, K. Nakamura T. Miyagawa, Y. Ichimura, T. Taniguchi, A. Yoshizaki, S. Sato. Dermatology, University of Tokyo, Graduate School of Medicine, Tokyo, Japan

Background: Systemic sclerosis (SSc) is a systemic connective tissue disease characterised by autoimmunity, vascular disorder and fibrosis of skin and other organs (1). Although substantial reports have been hitherto provided upon its pathogenesis in relation to microvasculature, among which are on endothelial and fibroblastic Fli1 deficiencies $(1,2)$, adequate investigation into hemocytic involvement is yet to be attained. Platelets are well known for its function in hematostasis whereas they also play a part in inflammation, immunity and cellular proliferation (3), thus prompting us to speculate their cardinal role in the development of the disease.

Objectives: Here we aim to unravel the role of platelets in the pathogenesis of SSc, with generation of platelet-specific conditional Fli1 knockout (Fli1 PcKO) mice to scrutinise its dermal wound healing process.

Methods: We generated Fli1 PcKO mice using the Cre-Lox system along with PfCre +/- mice as an appropriate control. We made two excisional wounds on the dorsal skin of each mouse (three months old) using an eight-millimeter-diameter punch and traced the wound surfaces every other day to measure their areas using Image $\mathrm{J}$ until all the wounds were epithelised. On a separate experiment, perilesional skin was harvested on the day two, from which we extracted mRNA for the measurement of proinflammatory and profibrotic cytokines. An immunostaining for $\alpha$-SMA was performed on the skin samples.

Results: The areas of the wounds were calculated and shown in ratio to their initial areas (day 0). Fli1 PcKO mice showed a significant decrease in the areas compared to the control on day 2. mRNA measurement revealed a significant increase in Mmp13 and significant decreases in Tgfb1, Ifng and /I13 for Fli1
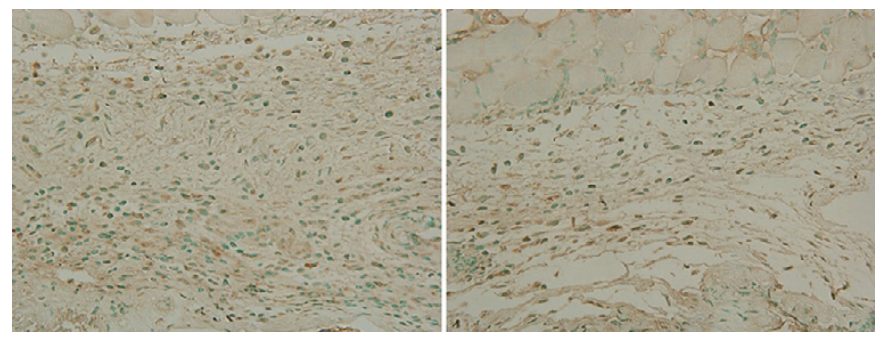

PcKO. In histopathology, $\alpha$-SMA positive fusiform-shaped cells were abundant in the granulation tissue of Fli1 PcKO mice (Figure; left, PfCre +/-; right, Fli1 PcKO; original magnification, $\times 400)$.

Conclusions: In dermal injuries on Fli1 PcKO mice, inflammatory disturbances precipitate myofibroblast formation in the granulation tissue, thus anticipating wound closure by mechanical contraction.

\section{References:}

[1] Asano Y et al., Curr Rheumatol Rep. 2013; 15(12):382.

[2] Asano $Y$ et al. Am J Pathol. 2010; 176(4):1983-98.

[3] Ramirez GA et al., Front Immunol. 2012; 3:160.

Disclosure of Interest: None declared

DOI: 10.1136/annrheumdis-2017-eular.1350

\section{OP0088 THE ROLE AND FUNCTION OF MONOCYTE-DERIVED FIBROBLAST-LIKE CELLS IN MULTI-ORGAN FIBROSIS IN SYSTEMIC SCLEROSIS}

M. Rudnik ${ }^{1}$, M. Stellato ${ }^{1}$, V. Milleret ${ }^{2}$, P. Błyszczuk ${ }^{3}$, B. Maurer ${ }^{1}$, K. Klingel ${ }^{4}$, J. Henes ${ }^{5}$, K. Sotlar ${ }^{6}$, M. Ehrbar ${ }^{2}$, O. Distler ${ }^{1}$, G. Kania ${ }^{1}$. ${ }^{1}$ Department of Rheumatology; ${ }^{2}$ Department of Obstetrics, Univeristy Hospital Zurich, Zurich, Switzerland; ${ }^{3}$ Department of Clinical Immunology, Jagiellonian University Medical College, Krakow, Poland; ${ }^{4}$ Department of Molecular Pathology; ${ }^{5}$ Department of Rheumatology, University Hospital Tuebingen, Tuebingen; ${ }^{6}$ Institute of Pathology, Ludwig Maximilian University, Munich, Germany

Background: Animal studies indicated bone marrow-derived cells as a source of pathological myofibroblasts in multiple organ fibrosis such as lungs, heart, skin and kidney. Monocytes are implicated in the pathogenesis of systemic sclerosis (SSc), however detailed role of specific monocyte subsets in multi-organ fibrogenesis in SSc remains unclear.

Objectives: We aimed to determine the role and the contribution of circulating monocytes in the onset and progression of multi-organ fibrosis in SSc.

Methods: Endomyocardial biopsies $(n=10)$ from SSc patients and healthy controls were screened by immunohistochemistry. CD14+ monocytes isolated from peripheral blood of SSc patients and healthy donors were differentiated towards a myofibroblast phenotype by stimulation with TGF- $\beta 1, \mathrm{IL}-4, \mathrm{IL}-10$ and IL-13. In addition, CD14+ monocytes were co-cultured in 2D and $3 D$ models with dermal fibroblasts originating from SSc patients or healthy subjects, or with adult cardiac fibroblasts. TGF- $\beta$ signalling was blocked by SD208 and A83-01 inhibitors. Profibrotic gene expression and protein secretion were evaluated by qPCR, Western blot, protein array, immunofluorescence and ELISA.

Results: The myocardia of SSc patients revealed the presence of CD45expressing infiltrates, an extended collagen I deposition and the presence of CD14-expressing elongated cells in the fibrotic tissue. Stimulated monocytes acquired a myofibroblast-like phenotype with increased expression of collagen I $(p<0.0001)$, fibronectin $(p<0.05)$, and $\alpha$ smooth muscle actin $(\alpha-S M A)$ in comparison to untreated cells. Similarly, CD14 ${ }^{+}$monocytes exposed to dermal or cardiac fibroblasts acquired spindle shape and expressed higher levels of profibrotic genes. The process of monocyte-to-myofibroblast differentiation employed TGF- $\beta /$ SMAD signalling. Blocking of the TGF- $\beta$ receptor I and canonical SMAD-dependent pathway with inhibitors resulted in the abrogation of collagen I secretion by monocytes $(p=0.002)$. CD14 ${ }^{+}$monocytes from SSc patients were characterised by higher secretion of CXCL10 $(p<0.001)$, which was significantly decreased after cytokine stimulation $(p<0.001)$. Additionally, a tendency towards higher secretion of CCL20, CCL22, Leukemia Inhibitory Factor and neurotrophin-3 was observed for SSc monocytes.

Conclusions: Here we demonstrated the capability of peripheral blood monocytes to differentiate towards the functional myofibroblast phenotype, designating these cells as one of the potential sources of pathological tissue myofibroblasts in SSc. Additionally, these cells sustained pro-fibrotic cytokines secretion, highlighting their important regulatory functions in the fibrogenesis in SSc. Further studies of monocytes involvement in SSc might lead to novel treatment strategies.

Disclosure of Interest: M. Rudnik: None declared, M. Stellato: None declared, V. Milleret: None declared, P. Błyszczuk: None declared, B. Maurer Grant/research support from: AbbVie, Protagen, EMDO, Novartis. Congress support from Pfizer, Roche, Actelion. Patent licensed: mir-29 for the treatment of systemic sclerosis, K. Klingel: None declared, J. Henes: None declared, K. Sotlar: None declared, M. Ehrbar: None declared, O. Distler Grant/research support from: Actelion, Bayer, Boehringer Ingelheim, Pfizer, Sanofi. Patent licensed: mir-29 for the treatment of systemic sclerosis, Consultant for: 4 D Science, Actelion, Active Biotec, Bayer, Biogenldec, BMS, Boehringer Ingelheim, ChemomAb, EpiPharm, espeRare foundation, Genentech/Roche, GSK, Inventiva, Lilly, medac, Mepha, Medlmmune, Mitsubishi Tanabe Pharma, Pharmacyclics, Pfizer, Sanofi, Serodapharm, Sinoxa, Speakers bureau: AbbVie, iQone Healthcare, Mepha, G. Kania Grant/research support from: Bayer

DOI: 10.1136/annrheumdis-2017-eular.3800 